\title{
Suzuki-Miyaura Coupling Revisited: An Integrated Computational Study
}

Received 00th January 20xx, Accepted 00th January 20xx

DOI: $10.1039 / \times 0 \times x 00000 x$

\author{
Tolga Yaman a and Jeremy N. Harvey*a
}

\begin{abstract}
New density functional theory (DFT) computations are reported concerning the mechanism of the Suzuki-Miyaura crosscoupling reaction of aryl halides and aryl boronic acids catalyzed by palladium phosphine complexes. The calculations are aimed at refining the understanding of the overall catalytic mechanism by using state of the art theoretical approaches (including for the first time an attempt to describe the Gibbs energy of the reactant base in a realistic way). New experimental results (Thomas and Denmark, Science, 2016, 352, 329-332) concerning pre-transmetallation intermediates with a $\mathrm{Pd}-\mathrm{O}-\mathrm{B}$ linkage provide an invaluable benchmark to test the accuracy of the calculations. The calculations show that bottlenecks to catalysis associated with oxidative addition, $\mathrm{X}$-to-O substitution at $\mathrm{Pd}$, and transmetallation can lie close in energy.
\end{abstract}

\section{Introduction}

Computational techniques based on quantum mechanical description of electronic structure have evolved to become one of the primary sources of information concerning reaction mechanisms in organometallic chemistry. From the point of view of the computational chemist, this is both a welcome recognition of the power of these techniques, and a daunting challenge given the many links in the logical chain that connects in silico models and experimental reality. Much of the focus in computational studies has traditionally been placed on obtaining qualitative insights into structure and bonding in different intermediates and transition states. However, in recent years, there has been a progressive shift towards attempting to obtain more quantitative predictions concerning the rates of individual steps or of overall transformations. In the context of cross-coupling catalysis, we have previously shown that it is possible to predict computationally which of the several related mechanisms for oxidative addition should be favoured for given aryl halide substrates and phosphine ligands. ${ }^{1}$ For the - computationally relatively tractable - case of cobalt-catalyzed hydroformylation, we have even been able to predict the rate of catalytic turnover with almost quantitative accuracy. ${ }^{2}$ To do this, we have predicted Gibbs energies for all relevant intermediates and TSs, and then predicted the kinetic behaviour of the resulting network of reaction steps. In this paper, we wish to start to carry out a similar process for a much more challenging reaction, namely, one of the most important cases of homogeneous organometallic catalysis, SuzukiMiyaura coupling of aryl halides and boronic acids.

The Suzuki-Miyaura coupling of boronic acids with aryl and vinyl halides ${ }^{3-8}$ is one of the most commonly-used palladiumcatalyzed organic transformations, and accordingly its reaction

\footnotetext{
a. Division of Quantum Chemistry and Department of Chemistry, KU Leuven, Celestijnenlaan 200F, B-3001 Leuven, Belgium.

Electronic Supplementary Information (ESI) available: Tables of calculated potential energies and of Gibbs energies; Cartesian coordinates for all optimized structures.
} See DOI: $10.1039 / x 0 x \times 00000 x$ mechanism has received extensive attention. Early on in the experimental development of this reaction, it was suggested that the key steps involved were precatalyst activation (to form a $\mathrm{Pd}(0)$ species), oxidative addition of the aryl halide to form a aryl-Pd(II) species, transmetallation with the boronic acid species $\mathrm{RBX}_{2}$ to form an aryl-Pd-R species, and reductive elimination. While there is evidence that in some cases, different chemistry involving dimeric palladium species or other oxidation states such as $\mathrm{Pd}(\mathrm{I})$ and $\mathrm{Pd}(\mathrm{IV})$ may be involved, ${ }^{9}$ it has since become the consensus that this is indeed the general mechanism for the reaction, and that will also be the focus in this study.

Each of the key steps has been the focus of many experimental ${ }^{10,11,12}$ and computational| ${ }^{13,14,15,16,17}$ mechanistic studies, which have in turn often led to guidelines for improved reactivity. Briefly, oxidative addition is known to be favoured with aryl iodides and bromides vs. chlorides, ${ }^{18}$ with other substrates such as esters also being possible in some cases. Also, lower coordination of the palladium centre by ligands is favourable, ${ }^{1}$ as is high electron density at the Pd centre, leading to the development of bulky electron-donating ligands. ${ }^{19}$ Most experimental conditions use phosphine ligands, but $\mathrm{N}$ heterocyclic carbenes ${ }^{20}$ have also been successfully used in some cases. ${ }^{21}$ Careful experimental kinetic studies have played an important role in uncovering these aspects, and there have also been many computational studies. Reductive elimination has also been extensively explored, both experimentally ${ }^{22,23}$ and computationally. ${ }^{24,25}$

It appears that the transmetallation step can be overall turnover-limiting for some variants of the Suzuki-Miyaura coupling, ${ }^{26}$ and accordingly there have been large numbers of studies addressing this step. ${ }^{27,28}$ These studies have addressed among other topics the dependence of reactivity on the nature of the boronic acid species, for example, investigating the differences in mechanism arising when using boronic acids 
$\mathrm{RB}(\mathrm{OH})_{2}$ as substrates compared to using the related trifluoroborate salts $\mathrm{RBF}_{3} \cdot \mathrm{M}(\mathrm{M}=\mathrm{K}, \mathrm{Na}) .^{29}$

There has been a lot of debate in the literature concerning the precise mechanism by which transmetallation from species 1 occurs, with two widely discussed possibilities being direct substitution by boronate $\mathbf{2}$, which is the "hydroxyboronate substitution' route which we will also refer to as "Path $\alpha$ ", and the indirect 'hydroxide substitution then boronic acid addition' route through hydroxide $\mathbf{3}$ followed by addition of boronic acid 4 or "Path $\beta$ " (Scheme 1). $30,31,32$

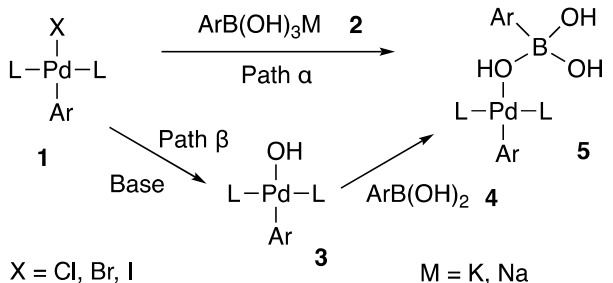

Scheme 1: Classical transmetallation pathways

Somewhat surprisingly given their centrality in suggested Suzuki-Miyaura coupling mechanisms, until recently, no pretransmetallation complexes containing a Pd-O-B connected motif, such as species 5 in Scheme 1 , had been isolated experimentally. This state of affairs changed following the careful work by Denmark and co-authors, who were able to characterize a number of such species using low-temperature NMR approaches. ${ }^{33,34}$ This led to a better understanding of the manifold of reactions that can occur during transmetallation, and in particular showed that Scheme 1 underestimates the complexity of the network of reactions that may be involved. Also, Scheme 1 perhaps places too much emphasis on the nature of the nucleophilic substitution step and not enough on the actual transmetallation step. ${ }^{33,34}$

As well as experimental and computational studies of individual steps in the catalysis, there have been a number of notable attempts to characterize the whole process, and here we especially wish to highlight the through computational study by Kozuch and Martin which attempted to derive general rules for designing a successful catalytic cycle based on the computational insight. ${ }^{35}$

In this study, we revisit the question of the overall mechanism of Suzuki coupling of boronic acids with aryl bromides catalysed by $\mathrm{PdL}_{n}$ species $\left(\mathrm{L}=\mathrm{P}-\mathrm{P{ } _ { 2 }}{ }_{3}, \mathrm{PPh}_{3}\right)$. Compared to our previous work on oxidative addition to $\mathrm{Pd}(0),{ }^{1}$ this study will require that we consider many more possible intermediates and reaction steps. Compared to our previous work on hydroformylation, ${ }^{2}$ we will need to deal with the complexity of a reaction taking place in multiple phases and involving many charged species (ions or ion pairs). We have found recently ${ }^{36}$ that obtaining accurate calculated Gibbs energies for such polar species remains very challenging, with maximum errors on Gibbs energies remaining of the order of $5 \mathrm{kcal} \mathrm{mol}^{-1}$ even when using highly accurate quantum-chemical methods. Nevertheless, the new experimental data relating to new pre-transmetallation intermediates and the kinetics of their conversion to products provides a new opportunity to test the accuracy of computational work in the field, and motivates this study.

\section{Computational details}

All calculations were performed using DFT, with the Gaussian 16 program package. ${ }^{37}$ All intermediate and transition state geometries were optimized with the B3LYP functional as implemented in Gaussian, together with Grimme's D3-BJ38 dispersion correction and the SMD continuum solvation mode ${ }^{39}$ with parameters appropriate for THF as the solvent. For several species, we found that explicit representation of a THF molecule leads to a lower Gibbs energy than when using only the continuum model of THF. This typically occurs when a metal-coordinated oxygen atom bears a hydrogen atom, which can donate a hydrogen bond to THF. At $293.15 \mathrm{~K}$, this leads to a significantly lower free energy for one species (15 in Fig. 1), and accordingly the Gibbs energy shown below refers to that explicitly solvated structure. For $\mathrm{Br}, \mathrm{Pd}$, and I atoms, effective core potentials from the Stuttgart group, and associated triple zeta basis sets were used (with the 'SDD' keyword in Gaussian) as implemented in Gaussian; whereas for all other atoms the 6$31 \mathrm{~g}(\mathrm{~d})$ basis set, also as implemented in Gaussian, was used. Frequency calculations were carried out at the optimized structures at the same level of theory. All transition states were identified by having one negative eigenvalue in the Hessian matrix. Based on the masses, rotational constants and vibrational frequencies obtained in this way for each species, Gibbs energy corrections were calculated using the quasiharmonic approximation ${ }^{40}$ whereby vibrational frequencies with a magnitude smaller than $100 \mathrm{~cm}^{-1}$ were set to $100 \mathrm{~cm}^{-1}$ for the statistical mechanical treatment. For the translational partition function, a volume corresponding to a standard state concentration of $1 \mathrm{~mol} \mathrm{dm}^{-3}$ was used for all species, except for gas phase species ( 1 bar standard state) and THF solvent (12.3 $\mathrm{mol} \mathrm{dm}^{-3}$ ). Single point energies at the optimized structures were calculated, also with the B3LYP functional, the D3-BJ dispersion correction and the SMD continuum model for THF, but using a larger basis set. This used for $\mathrm{Br}, \mathrm{Pd}$, and I atoms the Ahlrichs Def2QZVPP basis set (which includes an ECP for core electrons for $\mathrm{Pd}$ and $\mathrm{I}$ ), whereas the other atoms were treated with the Ahlrichs Def2TZVP basis set as implemented in Gaussian.

To identify the preferred conformation for all species, a number of different starting structures were used, and the reported results correspond to the structure with the lowest Gibbs energy at the level just described (in some cases structures of alternative conformations are included in the supporting information). This issue is particularly important in the case of species containing the $\mathrm{P}_{-} \mathrm{Pr}_{3}$ ligand, which has complicated conformational behaviour, and considerable care has been taken to identify favoured conformers. 


\section{Results and discussions}

One of the major challenges associated with carrying out modelling relating to the mechanism of Suzuki-Miyaura coupling is the sheer diversity of reactions and reaction conditions that fall under this name. As mentioned in the Introduction, we restrict ourselves here to coupling with palladium, to reactions taking place in tetrahydrofuran (THF) solvent, to tris(isopropyl) phosphine $\left(\mathrm{P}-\mathrm{Pr}_{3}\right)$ or triphenyl phosphine $\left(\mathrm{PPh}_{3}\right)$ as the ligands, to $p$-fluorophenyl boronic acid as the nucleophile, to $p$-fluorophenyl iodide or bromide as the electrophile, and to solid $\mathrm{Na}_{2} \mathrm{CO}_{3} \cdot \mathrm{H}_{2} \mathrm{O}$ as the base. For the Gibbs energy calculations, we also need to assign the temperature, and many different values could in principle be chosen with reference to different experiments. For simplicity, we have picked $T=293 \mathrm{~K}\left(20{ }^{\circ} \mathrm{C}\right)$ as the standard temperature for thermodynamic analysis for all species. As many of the target experiments were performed at lower temperature, we also computed thermal corrections at $-30{ }^{\circ} \mathrm{C}(243 \mathrm{~K})$ and these values are included in the SI. Reaction with anhydrous $\mathrm{Na}_{2} \mathrm{CO}_{3}$ in anhydrous THF is not usually possible, and our calculations allow for the presence of a small amount ( $1 \mathrm{M}=1 \mathrm{~mol} \mathrm{dm}^{-3}$ ) of water in the THF. By and large all these choices reflect common practice when carrying out Suzuki-Miyaura coupling, as well as the conditions used in the new mechanistic work from the Denmark group mentioned in the Introduction. ${ }^{33,34}$

Quantitative work in mechanistic chemistry requires attention to many aspects concerning the level of electronic structure theory, the treatment of solvation, the calculation of entropic contributions, the exploration of the different conformers for each species in the reaction mechanism, and so on. ${ }^{41}$ In this study, we have opted for a relatively straightforward methodology, based on the B3LYP DFT functional, flexible basis sets for optimization and single-point energy evaluation, a continuum model of solvent, 42 and full inclusion of entropic effects. Based on our previous experience, ${ }^{36}$ though, it should be remembered that this type of approach can lead to errors in predicted relative Gibbs energies of $5 \mathrm{kcal} \mathrm{mol}^{-1}$ or more.

Within this chosen modelling framework, we have considered a number of different mechanistic steps, and now describe our results for these in the following sections. Note that we have not reported any new calculations on the oxidative addition of the electrophile to $\operatorname{Pd}(0)$, as this has already been extensively studied by us ${ }^{1}$ and others. ${ }^{9-12}$

\subsection{Speciation of boronic acid}

Boronic acid derivatives have been the most commonly used nucleophilic partners in Suzuki-Miyaura coupling, ${ }^{43}$ and choice of them in addition to the choice of base can play an important role. There are some recent examples of the usage of stable metal tri-hydroxy-boronate complexes ${ }^{44}$ directly without the use of a base. ${ }^{32}$ We start by taking a closer look at the energetics of the reaction of a neutral boronic acid molecule $\operatorname{ArB}(\mathrm{OH})_{2}$ reacting with different bases to produce its $\operatorname{ArB}(\mathrm{OH})_{3}$ derivative, with different modelling assumptions (Table 1).

The most common approach in the computational literature has been to model the base directly as an $\mathrm{OH}^{-}$anion, or an $\mathrm{OH}^{-}$ anion in coordination with water. ${ }^{32}$ Using the simplest approach, the reaction $p-\mathrm{FC}_{6} \mathrm{H}_{4} \mathrm{~B}(\mathrm{OH})_{2}+\mathrm{OH}^{-} \longrightarrow p-\mathrm{FC}_{6} \mathrm{H}_{4} \mathrm{~B}(\mathrm{OH})_{3}^{-}$ is calculated to be very favourable in Gibbs energy, which would suggest that under basic conditions typical for Suzuki-Miyaura coupling, boronic acids would always be present as their boronate conjugate bases. However, continuum models underestimate the solvation Gibbs energies of small, high charge-to-radius ratio anions such as hydroxide, and this is particularly true in the case of THF/water mixtures that are commonly used in such reactions. Using our default $\mathrm{H}_{2} \mathrm{O}$ concentration of $1 \mathrm{M}$, we calculate that species $\mathrm{OH}^{-} .\left(\mathrm{H}_{2} \mathrm{O}\right)_{n}(n=$ $1-3)$ are lower in Gibbs energy than separate $\mathrm{OH}^{-}$and $n \mathrm{H}_{2} \mathrm{O}$, with the lowest Gibbs energy being returned for $n=3$. Likewise, the bare boronate $p-\mathrm{FC}_{6} \mathrm{H}_{4} \mathrm{~B}(\mathrm{OH})_{3}{ }^{-}$is stabilized by hydrogen bonding to three water molecules. This leads to a modified estimate for the relative Gibbs energy of the boronate taking into account the solvation by water molecules, which is less favourable. Our relative Gibbs energy in Table 1 is similar to that reported by Ortuno et al. ${ }^{32}$

Table 1: Computed relative Gibbs energies $\left(/ \mathrm{kcal} \mathrm{mol}^{-1}\right)$ for formation of boronate anion $p$ - $\mathrm{FC}_{6} \mathrm{H}_{4} \mathrm{~B}(\mathrm{OH})_{3}{ }^{-}$at $293 \mathrm{~K}$ in THF (with $1 \mathrm{M} \mathrm{H}_{2} \mathrm{O}$ ). Ar denotes $p-\mathrm{FC}_{6} \mathrm{H}_{4^{-}}$. The detail of the reaction modelled is shown in each case. Unless otherwise specified, each species is treated in THF continuum solvent.

\begin{tabular}{ccc}
\hline Base & $\begin{array}{c}\text { Boronate } \\
\text { Reaction modelled }\end{array}$ & $\Delta G^{0}$ \\
\hline $\mathrm{OH}^{-}$ & $\mathrm{ArB}(\mathrm{OH})_{3}{ }^{-}$ & -36.2 \\
& $\mathrm{OH}^{-}+\mathrm{ArB}(\mathrm{OH})_{2} \rightarrow \mathrm{ArB}(\mathrm{OH})_{3}{ }^{-}$ & \\
$\mathrm{OH}^{-}\left(\mathrm{H}_{2} \mathrm{O}\right)_{3}$ & $\mathrm{ArB}(\mathrm{OH})_{3}{ }^{-}\left(\mathrm{H}_{2} \mathrm{O}\right)_{3}$ & -14.3 \\
$\mathrm{OH}^{-}\left(\mathrm{H}_{2} \mathrm{O}\right)_{3}+\mathrm{ArB}(\mathrm{OH})_{2} \rightarrow \mathrm{ArB}(\mathrm{OH})_{3}{ }^{-}\left(\mathrm{H}_{2} \mathrm{O}\right)_{3}$ & \\
$\mathrm{Na}_{2} \mathrm{CO}_{3} \cdot \mathrm{H}_{2} \mathrm{O}_{(\mathrm{s})}$ & $\mathrm{ArB}(\mathrm{OH})_{3}{ }^{-} \mathrm{Na}^{+}(\mathrm{THF})_{2}$ & +18.5 \\
$\mathrm{ArB}(\mathrm{OH})_{2}+\mathrm{Na}_{2} \mathrm{CO}_{3} \cdot \mathrm{H}_{2} \mathrm{O}_{(\mathrm{s})}+2 \mathrm{THF} \rightarrow \mathrm{NaHCO}_{3(\mathrm{~s})}+\mathrm{ArB}(\mathrm{OH})_{3}{ }^{-} \cdot \mathrm{Na}^{+}(\mathrm{THF})_{2}$
\end{tabular}

However, using solution phase hydroxide in any form may not be appropriate, and could lead to an exaggeration in the predicted basicity of the reaction conditions. In many cases the base employed in the Suzuki-Miyaura coupling is a weak base, often solid sodium or potassium carbonate, or these bases dissolved in a separate aqueous phase. ${ }^{43,45}$ Accordingly, we have instead used an approach whereby the base is modelled as solid $\mathrm{Na}_{2} \mathrm{CO}_{3} \cdot \mathrm{H}_{2} \mathrm{O}$. This raises the question as to how such a base can be included in a computational thermodynamic scheme based on molecular quantum chemical computations. The approach used here is one that we have used previously on several occasions for other solid reactants or by-products (originally for solid ZnO in ref. 46). Experimental data is obtained for the Gibbs energy of the target solid and of appropriate gasphase species containing the same elements. This is then combined with computed Gibbs energies for the gas-phase species, and for the desired solution-phase species, which allows a thermodynamic cycle to be closed, and inclusion of the solid species in the calculated Gibbs energy profile.

In the present case, we wish to calculate the Gibbs energy change for formation of the boronate anion, starting from solid $\mathrm{Na}_{2} \mathrm{CO}_{3} \cdot \mathrm{H}_{2} \mathrm{O}_{(\mathrm{s})}$, using the reaction shown. For this purpose, we take the experimental ${ }^{47,48} \mathrm{Gibbs}$ energy change for the reaction $\mathrm{Na}_{2} \mathrm{CO}_{3} \cdot \mathrm{H}_{2} \mathrm{O}_{(\mathrm{s})} \longrightarrow 2 \mathrm{Na}_{(\mathrm{g})}+\mathrm{CO}_{2(\mathrm{~g})}+1 / 2 \mathrm{O}_{2(\mathrm{~g})}+\mathrm{H}_{2} \mathrm{O}_{(\mathrm{g})}(+197.2 \mathrm{kcal}$ $\left.\mathrm{mol}^{-1}\right)$, and the corresponding value for $\mathrm{NaHCO}_{3}\left(\mathrm{NaHCO}_{3(\mathrm{~s})} \rightarrow\right.$ 
$\mathrm{Na}_{(\mathrm{g})}+\mathrm{CO}_{2(\mathrm{~g})}+1 / 2 \mathrm{O}_{2(\mathrm{~g})}+1 / 2 \mathrm{H}_{2(\mathrm{~g})}$, which is $\left.+128.4 \mathrm{kcal} \mathrm{mol}^{-1}\right)$. Together with DFT-computed values for the gas-phase Gibbs energies of $\mathrm{Na}, \mathrm{H}_{2} \mathrm{O}, \mathrm{O}_{2}, \mathrm{H}_{2}$, and $\mathrm{CO}_{2}$, this allows us to assign quantum-chemical 'Gibbs energies' to the solids $\mathrm{Na}_{2} \mathrm{CO}_{3} \cdot \mathrm{H}_{2} \mathrm{O}$ and $\mathrm{NaHCO}_{3}$, and thereby to obtain the relative Gibbs energy for the conversion described above, as shown in Table 1. This procedure amounts to combining experimental Gibbs energies for the solid bases and a DFT-derived Gibbs energy change for the reaction $\mathrm{ArB}(\mathrm{OH})_{2(\mathrm{THF})}+1 / 2 \mathrm{O}_{2(\mathrm{~g})}+1 / 2 \mathrm{H}_{2(\mathrm{~g})}+\mathrm{Na}_{(\mathrm{g})}+2 \mathrm{THF}_{(\mathrm{THF})}$ $\rightarrow \mathrm{ArB}(\mathrm{OH})_{3} \cdot \mathrm{Na}^{+}(\mathrm{THF})_{2(\mathrm{THF})}$. Note that this reaction is far from being isodesmic, and involves quite large changes in electronic structure, so the procedure used here is subject to errors arising from the DFT treatment of the gaseous species such as the sodium atom. This error is mitigated by the good performance of B3LYP for atomization energies and the use of a large basis for the single-point energies. Nevertheless, this procedure likely leads to additional errors for this reason. A refined procedure could be put in place where additional high-level quantum chemical computations are performed (e.g. $\operatorname{CCSD}(\mathrm{T})$ with large basis sets and/or explicit correlation treatment) for the gasphase species).

The value of this procedure is that it provides a complementary assessment of the relative Gibbs energy of the boronate, which is now significantly higher than that of the boronic acid, counter to the estimate where solution phase hydroxide was used as a reference point. This suggests that the equilibrium between boronic acid and boronate could be highly dependent on reaction conditions. It has been shown that boronate and boronic acid are present in roughly equal amounts in presence of potassium carbonate, ${ }^{29,30}$ but these observations relate to dissolved carbonate in roughly 1:1 THF:water and acetone:water mixtures, respectively. The present calculations suggest that in THF solvent with low water concentration, assuming carbonate is not dissolved, the equilibrium should instead be highly on the side of the boronic acid. Given the above caveats about the accuracy of the procedure, the value shown in Table 1 must be understood to be associated with some error, but the trend whereby boronate formation is much less favourable than when modelled with reference to solutionphase hydroxide should be correct.

\section{$3.2 \mathrm{X}$ to $O$ substitution}

A lot of previous work on the transmetallation step in SuzukiMiyaura coupling has focussed on this reaction step, namely the replacement of a halide group at palladium by an oxygencontaining nucleophile. As mentioned above, there has been a lot of debate concerning the mechanism of this step. ${ }^{29-31}$ Computationally, the state of affairs seems to be that path 1 in Scheme 1 is predicted to be preferred. In perhaps the most thorough computational study, ${ }^{24}$ the Gibbs energy barrier for substitution of bromide in $\mathrm{PhPd}\left(\mathrm{PPh}_{3}\right)_{2} \mathrm{Br}$ by $\mathrm{PhB}(\mathrm{OH})_{3}{ }^{-}$was calculated to be $18.9 \mathrm{kcal} \mathrm{mol}^{-1}$ in a model where the boronate anion was solvated by three explicit water molecules as well as by a continuum model. The Gibbs energy barrier for substitution by hydroxide anion (also treated as being solvated by three water molecules) was lower, at $16.9 \mathrm{kcal} \mathrm{mol}^{-1}$ (and the barrier for substitution by 'naked' hydroxide, surrounded only by continuum model of solvent, was much lower, at $8.3 \mathrm{kcal} \mathrm{mol}^{-1}$ ). However, hydroxide anion was computed - as here in section 3.1 - to bind strongly to boronic acid, and when taking this into account, overall, the 'direct' route had a lower Gibbs energy barrier in the computations. ${ }^{24}$ Our own test calculations show that TS structures and relative energies are very similar with $L=$ $\mathrm{P}(\mathrm{iPr})_{3}$ and with $\mathrm{L}=\mathrm{PPh}_{3}$, and accordingly, we have not explored this issue again in detail, instead relying on the results from ref. 24.

On the other hand, experimental studies have argued that the indirect route for substitution is preferred. Carrow and Hartwig measured the rate for reaction of $\mathrm{PhPd}\left(\mathrm{PPh}_{3}\right)_{2} \mathrm{Br}$ with $p$ tolylB(OH$)_{3}{ }^{-} \mathrm{K}^{+}$in 50:1 THF:water mixture in presence of 18crown-6 at several temperatures including $-30{ }^{\circ} \mathrm{C}$ and room temperature $\left(25^{\circ} \mathrm{C}\right)$, and found slow conversion at $-30^{\circ} \mathrm{C}(10 \%$ after $11 \mathrm{~h}$ ). Analysis of their observed rate constant at room temperature (see $\mathrm{SI}$ ) yields an estimated Gibbs energy barrier of about $16.1 \mathrm{kcal} \mathrm{mol}^{-1}$, fairly close to the calculated value of 18.9 kcal mol-1 mentioned above. The same authors find that $\mathrm{PhPdL}_{2} \mathrm{OH}\left(\simeq 10^{-3} \mathrm{M}\right)$ and $\mathrm{PhPdL}_{2} \mathrm{Br}\left(\mathrm{L}=\mathrm{PPh}_{3}, \mathrm{PCy}_{3}\right)$ interconvert rapidly to reach roughly equimolar concentrations at room temperature in THF:water (50:1 or 25:1) in presence of tetrabutylammonium bromide $\left(\simeq 10^{-3} \mathrm{M}\right.$; rapid equilibrium is also observed for chloride and iodide species). Specifically, they find that equilibrium is reached during the time needed to carry out ${ }^{31}$ P NMR spectroscopy, i.e. in less than 5 minutes, implying that the reaction of tetrabutylammonium hydroxide with $\mathrm{PhPdL}_{2} \mathrm{Br}$ is rapid also. The observed timescale translates into a half-life for reaction of less than roughly 30 seconds, which analysis shows (see SI) corresponds to an upper bound to the Gibbs energy barrier of $12.5 \mathrm{kcal} \mathrm{mol}^{-1}$. This value is somewhere in between the computational estimates of 8.3 and $16.9 \mathrm{kcal}$ $\mathrm{mol}^{-1}$ deriving from models with no microscopic hydration of the hydroxide anion and with three-fold hydration, respectively. ${ }^{32}$ Given that the experiments are performed in 25:1 THF:water, and that the $n$-butylammonium counterion, neglected in the computations, may play some role, again, this agreement is reasonable. In any case, it is clear that experimentally, a lower Gibbs energy barrier has been found for substitution by hydroxide than by trihydroxyboronate.

It should be pointed out, though, that this does not contradict the results from computation. As mentioned above, the computations only predict that the 'direct' route is overall favoured once one takes into account the fact that hydroxide binds very strongly to boronic acid. ${ }^{24}$ This factor is not accounted for in the above experimental comparison of rates. ${ }^{30}$ Even the computational study ${ }^{24}$ acknowledges that intrinsically, the 'indirect' route is somewhat more favourable, and thereby might be expected to compete under some conditions.

Other experiments ${ }^{31}$ consider turnover for reaction of $\operatorname{ArPd}\left(\mathrm{PPh}_{3}\right)_{2} \mathrm{X}$ (for $\mathrm{X}=\mathrm{Cl}, \mathrm{Br}$ and $\mathrm{I}$ and $\mathrm{Ar}=p$-substituted phenyl) with $\mathrm{Ar}^{\prime} \mathrm{B}(\mathrm{OH})_{2}$ ( $A r^{\prime}$ is $\mathrm{Ph}$ or another substituted phenyl group) in the presence of tetrabutylammonium hydroxide, in DMF solution at $25{ }^{\circ} \mathrm{C}$. The authors observe conversion to product with a complicated type of dependence on the concentration of hydroxide and boronic acid - increased hydroxide initially leads to faster conversion, but higher concentrations then lead to 
slower conversion again. For $\mathrm{X}=\mathrm{Br}$ and $\mathrm{PhB}(\mathrm{OH})_{2}$, the rate peaks for $\left[\mathrm{OH}^{-}\right]_{0} \simeq 0.7\left[\mathrm{PhB}(\mathrm{OH})_{2}\right]_{0}$. The same authors report ${ }^{31}$ that $\mathrm{PhB}(\mathrm{OH})_{3}{ }^{-}$is completely unreactive towards $(p-\mathrm{CN}$ $\mathrm{Ph}) \mathrm{Pd}\left(\mathrm{PPh}_{3}\right)_{2} \mathrm{Br}$ and thereby rule out the 'direct' mechanism completely. Despite the use of a different solvent, this observation seems hard to reconcile with the observation by Carrow and Hartwig of a rate of reaction of $\mathrm{PhPd}\left(\mathrm{PPh}_{3}\right)_{2} \mathrm{Br}$ with $p$-tolylB $(\mathrm{OH})_{3}{ }^{-} \mathrm{K}^{+}$in 50:1 THF:water, that is low at $-30{ }^{\circ} \mathrm{C}$ but quite high at room temperature. The authors also reported ${ }^{31} \mathrm{a}$ detailed kinetic analysis of their results, concluding that the indirect route occurs, and that the peculiar inversion of the reactivity trend with increasing hydroxide amounts is due to competition between $\mathrm{OH}^{-}$substitution of $\mathrm{X}$ and trapping of $\mathrm{PhB}(\mathrm{OH})_{2}$ as unreactive boronate.

As already said, these authors rule out occurrence of the direct route, based on their observed unreactivity of $\mathrm{PhB}(\mathrm{OH})_{3}{ }^{-}$with $(p-\mathrm{CN}-\mathrm{Ph}) \mathrm{Pd}\left(\mathrm{PPh}_{3}\right)_{2} \mathrm{Br}$. Given the good agreement between the computational Gibbs energy barrier for this key step in the 'direct' route ${ }^{31}$ and the Gibbs energy barrier extracted from the experiments, as discussed above, it seems likely that this step can in fact occur. The reason why it is not observed in the experimental study by Amatore et al. ${ }^{31}$ may relate to peculiarities of the solvent used (DMF vs. THF) or of the electrochemical detection method, or of the way in which the experimental results were analysed.

In summary for this section, both hydroxide and boronate $\mathrm{ArB}(\mathrm{OH})_{3}{ }^{-}$seem to be able to carry out substitution of $\mathrm{Pd}$-bound $X$ with barriers of the order of $15 \mathrm{kcal} \mathrm{mol}^{-1}$. Computation shows that hydroxide - which is expected to be a better nucleophile reacts over a slightly lower barrier than boronate, though under some conditions will also be present in much smaller amounts. Indeed, based on the results of the previous section, under many typical conditions for Suzuki-Miyaura coupling, the concentration of both hydroxide and boronate will be rather low, which means that the reactant species for the paths shown in Scheme 1 will not be present in large amounts. This will also impact on the overall thermodynamics of halide to hydroxide substitution. Using a similar protocol as in section 3.1 for treating solid sodium bromide, carbonate and bicarbonate, the reaction: $\mathrm{ArPdL}_{2} \mathrm{Br}(\mathrm{THF})+\mathrm{Na}_{2} \mathrm{CO}_{3} \cdot \mathrm{H}_{2} \mathrm{O}_{(\mathrm{s})} \rightarrow \mathrm{ArPdL}_{2} \mathrm{OH}+$ $\mathrm{NaHCO}_{3(\mathrm{~s})}+\mathrm{NaBr}_{(\mathrm{s})}$ is predicted to be rather unfavourable in Gibbs energy terms, by $+13.7 \mathrm{kcal} \mathrm{mol}^{-1}$. In more base-rich media, with e.g. mixtures of THF and water or acetone and water, with significant solution-phase concentration of carbonate, however, the step may be less unfavourable thermodynamically.

\subsection{Pre-transmetallation species}

We next turn to the question of the speciation of compounds formed following the $X$ to $O$ substitution, especially those containing a Pd-O-B linkage. In Scheme 2, we have shown two possible products from this substitution, the hydroxide $\mathbf{3}$ and the boronate 5. As already shown by Carrow and Hartwig, ${ }^{30}$ analogues of $\mathbf{3}$ react rapidly with boronic acid, presumably to form species such as $\mathbf{5}$. However, the new experiments from the Denmark group ${ }^{33,34}$ have shown that $\mathbf{5}$ is not stable under cross-coupling conditions. Instead, under phosphine-rich conditions (more than two equivalents of ligand per $\mathrm{Pd}$ ), species 6 is formed when reacting $\mathbf{3}$ with boronic acid, as a result of spontaneous dehydration of $\mathbf{5}$. The same species $\mathbf{6}$ can be formed by reacting $\mathbf{3}$ with boroxine 7 . Under phosphine-poor conditions (one L per Pd), the dimer 8 instead yields the cyclic dipalladium complex $\mathbf{9}$. Both 6 and 9 could be identified by NMR, and constitute the first well-characterized pretransmetallation intermediates with $\mathrm{Pd}$-O-B linkages.

Our calculations (Table 2) indeed confirm that $\mathbf{5}$ is somewhat more stable than $\mathbf{3}+\mathbf{4}$, with the dehydrated $\mathbf{6}$ lying even lower in Gibbs energy (we find 6 to lie $4.6 \mathrm{kcal} \mathrm{mol}^{-1}$ below $\mathbf{5}$, similar to the difference of $10.8 \mathrm{kcal} \mathrm{mol}^{-1}$ reported in ref. 34 , bearing in mind the significant changes in computational protocol). The calculations also show that the corresponding reaction with $\mathbf{7}$ is favourable in Gibbs energy terms. Also, even though the corresponding reactions with $\mathrm{PPh}_{3}$ have not been performed, our calculations show that the calculated Gibbs energies are rather similar with this ligand. It should be noted here that species 3, 5, and $\mathbf{6}$ can exist as cis or trans isomers, with the values reported here being for the more stable trans isomer. Values for the cis isomers can be found in the $\mathrm{SI}$ or in the literature for some species..$^{35}$ Full exploration of the mechanism for the water loss goes beyond the scope of this paper, but a preliminary investigation yielded a TS lying $22.4 \mathrm{kcal} \mathrm{mol}^{-1}$ higher in Gibbs energy than 5. Our TS structure is for a simple intramolecular water loss with an unfavourable 4-memberedring structure - lower Gibbs energy pathways involving shuttling of proton and/or intermediate proton transfer will certainly exist.

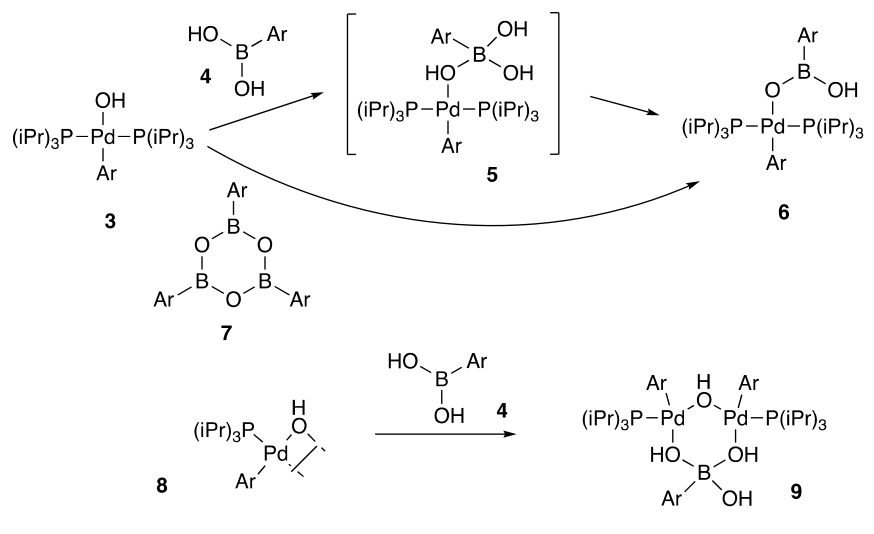

Scheme 2: Synthetic route for pre-transmetallation intermediates 6 and 9

Table 2: Computed relative Gibbs energies (/ $\mathrm{kcal} \mathrm{mol}^{-1}$, THF, $293 \mathrm{~K}$ ) for pretransmetallation species.

\begin{tabular}{|c|c|c|}
\hline Species & $\Delta G^{0} \mathrm{P}(\mathrm{iPr})_{3}$ & $\Delta G^{0} \mathrm{PPh}_{3}$ \\
\hline $3+4$ & 0.0 & 0.0 \\
\hline 5 & -2.8 & -0.7 \\
\hline $6+\mathrm{H}_{2} \mathrm{O}$ & -7.4 & -7.3 \\
\hline $3+1 / 37+\mathrm{H}_{2} \mathrm{O}$ & 0.3 & 0.2 \\
\hline $2 \times 3+4$ & 0.0 & 0.0 \\
\hline $8+4+2 \times \mathrm{PR}_{3}$ & 12.0 & 3.8 \\
\hline $9+2 \times \mathrm{PR}_{3}$ & 11.3 & 3.7 \\
\hline
\end{tabular}


Calculations and optimization were also carried out on species 8 and 9 that are relevant under low-phosphine conditions. Formation of $\mathbf{8}$ by loss of phosphine from two equivalents of $\mathbf{3}$ is found to be unfavourable with both $\mathrm{L}=\mathrm{P}(\mathrm{iPr})_{3}$ and $\mathrm{PPh}_{3}$, although only just in the latter case. Indeed, in the presence of excess $\mathrm{P}(\mathrm{iPr})_{3}, \mathbf{8}$ is known to convert to $\mathbf{3} .^{34}$ Likewise, $\mathbf{9}$ lies higher in Gibbs energy compared to $\mathbf{6}$, and indeed addition of excess phosphine is known to convert 9 to 6 (see Scheme 22 in ref. 34). Species 9 is calculated to be nearly equal in Gibbs energy to 8 at $293 \mathrm{~K}\left(-0.7 \mathrm{kcal} \mathrm{mol}^{-1}\right)$. The thermodynamic driving force is larger at lower temperatures (see $\mathrm{SI}$ ), consistent with the fact that NMR characterization of $\mathbf{9}$ is feasible only at low temperature. A possible route from hydroxide 8 and boronic acid 4 to the six-membered ring species 9 has been explored computationally, see below in Figure 2 .

Our calculations hereby confirm the stability of the key observed species 6 and $\mathbf{9}$. Indeed, formation of $\mathbf{6}$ from the hydroxide species $\mathbf{3}$ is sufficiently favourable in Gibbs energy terms that even using solid $\mathrm{Na}_{2} \mathrm{CO}_{3} \cdot \mathrm{H}_{2} \mathrm{O}$ as a base, this pretransmetallation species, having a $\mathrm{Pd}-\mathrm{O}-\mathrm{B}$ linkage, should be competitive in terms of Gibbs energy with the $\mathrm{ArPdL}_{2} \mathrm{Br}$ oxidative addition species 1 . At room temperature, we calculate that 6 lies just $6.3 \mathrm{kcal} \mathrm{mol}^{-1}$ above 1.

\subsection{Transmetallation and reductive elimination}

In this section, we discuss our results relating to the transmetallation itself, which is often described as being the most complex and least understood step. ${ }^{49}$ It leads to formation of a diaryl Pd(II) species, which can then undergo reductive elimination. As for the other steps, there have been many previous computational studies. ${ }^{50,51}$ There has recently developed a consensus that transmetallation starts from species with just one phosphine ligand, such as $\mathbf{1 0}$ or $\mathbf{1 1}$ in Scheme 3, as reactions starting from bisligated species such as 5 or $\mathbf{6}$ were calculated to be less favourable. ${ }^{17}$ The Gibbs energy needed to lose a phosphine from species $\mathbf{5}$ or $\mathbf{6}$ is compensated for by a higher intrinsic reactivity. Most previous studies have presented TSs originating from 10, however, kinetic data presented in the recent work on isolated Pd-O-B pretransmetallation species $^{34}$ showed an inhibitory role for excess water which was interpreted as favouring $\mathbf{1 1}$ as a direct precursor.

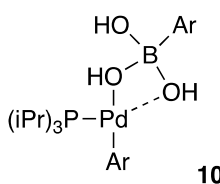
10

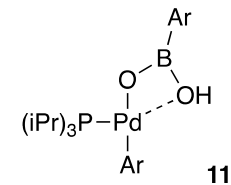

11
Scheme 3: Possible transmetallation initiator species $\mathbf{1 0}$ and $\mathbf{1 1}$

For consistency with our present work, which takes better account of dispersion effects, the corresponding TSs have been considered again here (Figure 1). In both cases, the overall process occurs in two main steps: first, the initial species (10 or 11) which involves the organoborate coordinating to $\mathrm{Pd}$ through two oxygen atoms converts to an O,C-chelating rotamer $\mathbf{1 2}$ or
13, after which the $\mathrm{B}-\mathrm{C}$ bond converts to a $\mathrm{Pd}-\mathrm{C}$ bond, and a cis-diaryl Pd(II) species $\mathbf{1 4}$ or $\mathbf{1 5}$ is formed through TSs TS1 or TS2. ${ }^{18}$ After loss of boric acid, the biarylpalladium species $\mathbf{1 6}$ (and its diphosphine variant 17) is formed, which can then undergo reductive elimination through TS3 to form biaryl 18 and $\mathrm{L}_{2} \mathrm{Pd}(0) 19$, which can then reinitiate the cycle.

In our calculations, TS1 lies considerably lower, by $10.9 \mathrm{kcal}$ $\mathrm{mol}^{-1}$ in Gibbs energy than TS2. TS2 leads to formation of a complex 15 between the bisarylpalladium species and a dehydrated form of boric acid, $\mathrm{HO}-\mathrm{B}=\mathrm{O}$. The latter is a rather unstable species, with formation of the more usual $\mathrm{B}(\mathrm{OH})_{3}$ from $\mathrm{HOBO}+\mathrm{H}_{2} \mathrm{O}$ calculated to be $33.6 \mathrm{kcal} \mathrm{mol}^{-1}$ favourable in Gibbs energy terms at our level of theory. This means that the step through TS2 is rather endothermic, and TS2 is a very late or product-like TS, lying just $3.7 \mathrm{kcal} / \mathrm{mol}$ higher in Gibbs energy than 15. These aspects can also be seen in the earlier computational work, ${ }^{34}$ where it was however argued that HOBO can be significantly stabilized by forming a cyclic trimer. This stabilization is however not possible in TS2. The high energy of TS2 appears to rule it out as a possible funnel for the actual transmetallation step, which must therefore instead proceed through TS1 or a similar route. The importance of TS2 was suggested based on the observed kinetic effect of added water on the reaction, ${ }^{34}$ but the present computational results lead us to suggest that this relatively small effect (adding ten equivalents of water to the reaction depresses the rate or transmetallation from 5 by a factor of two) may be due to other aspects of the chemistry of water in THF, which is known to be complicated. 45

The reductive elimination TS3 is similar to that reported in previous studies. ${ }^{35}$ It lies lower in Gibbs energy than TS1 by 9.0 $\mathrm{kcal} \mathrm{mol}^{-1}$ according to our calculations, suggesting that at least for this ligand and aryl groups, the reductive elimination step is unlikely to be kinetically relevant. Finally for this part the final biaryl product $\mathbf{1 8}$ is calculated and its Gibbs energy (together with that of the $\mathrm{Pd}(0)$ complex $\mathrm{Pd}\left(\mathrm{PiPr}_{3}\right)_{2}$ and $\left.\mathrm{B}(\mathrm{OH})_{3}\right)$ lies 47.9 $\mathrm{kcal} / \mathrm{mol}$ lower than that of $\mathbf{1 0}$, showing that it is the most stable product of this scheme as very much expected.

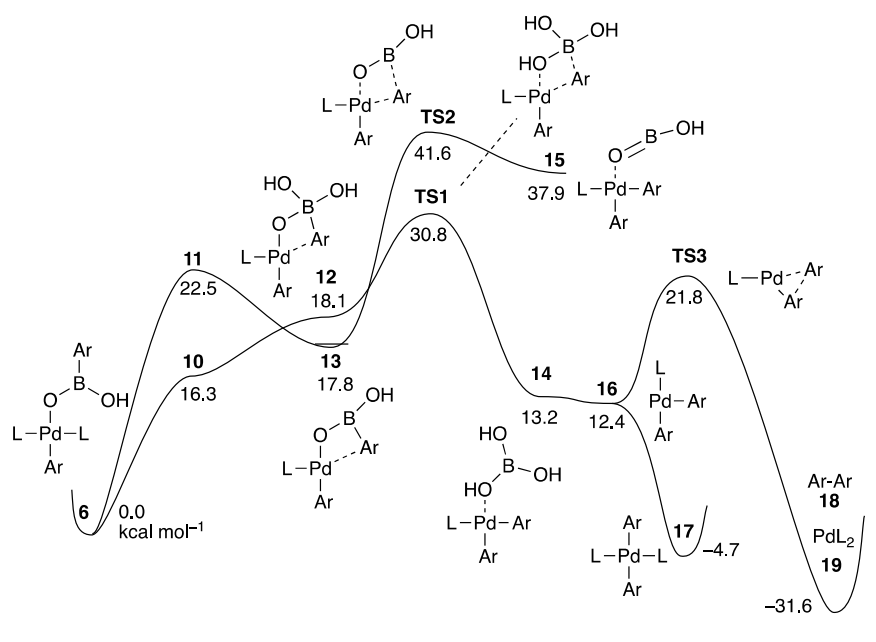

Figure 1: Calculated Gibbs energy profile ( $\mathrm{kcal} \mathrm{mol}^{-1}, 293 \mathrm{~K}$ ) for the transmetallation routes via $\mathbf{1 0}$ and $\mathbf{1 1}$. 
When the reaction is initiated from the dimeric $\mathrm{Pd}$ hydroxide species $\mathbf{8}$ containing just one phosphine ligand per Pd centre, in the absence of added ligand, the transmetallation route followed will be different (Figure 2). As already discussed in relation to Scheme 2, 8 can react with 4 to form 9 . The initial step involves formation of complex 20, which lies lower in potential energy but higher in Gibbs energy than the separated species. Intramolecular substitution through TS4 yields $\mathbf{9}$. The energy of TS4 obtained here is a bit high considering the observed $^{34}$ quite fast conversion of 8 to 9 at $173 \mathrm{~K}$; this discrepancy may be resolved if there are lower-energy TSs involving proton shuffling, but we have not explored these here. Adding a further boronic acid $\mathbf{4}$ yields (after rearrangement) complex 21, which can then split to form two equivalents of species 10, which can then react further as just discussed. Formation of $\mathbf{1 0}$ in this way is supported by the observation ${ }^{34}$ that reaction of $\mathbf{8}$ with a dimethyl boronic ester leads to an isolable dimethylester variant of $\mathbf{1 0}$. The same species can be formed from reaction of $\mathbf{8}$ with the normal boronic acid, followed by exposure to methanol.

The calculated Gibbs energies for the transmetallation step can be compared to the results from kinetics experiment starting from either species 6 (Figure 1 ) or species 8 (Figure 3). In the first case, $\mathbf{6}$ is formed in situ upon mixing $\mathbf{3}$ with boronic acid 4 (see Scheme 2), and the kinetics of decay of 6 to the final SuzukiMiyaura coupling product were measured at $293 \mathrm{~K}$, under various conditions including addition of water or various amounts of excess $\mathrm{P}(\mathrm{iPr})_{3}$. The observed rate of product formation is not very dependent on the conditions, but we compare here specifically to the experiment with no added water and with 2.85 equivalents of $\mathrm{P}(\mathrm{iPr})_{3}$, where product formation occurred with a rate constant of $4.8 \pm 0.65 \times 10^{-3} \mathrm{~s}^{-1}$, equivalent to a Gibbs energy barrier of $20.3 \mathrm{kcal} / \mathrm{mol}$. The overall Gibbs energy of activation relative to species 6 calculated here is $30.8 \mathrm{kcal} / \mathrm{mol}$, with TS1 being the bottle-neck. The substantial disagreement with experiment could be due to errors in the computational method, though it is also conceivable that an alternative TS to TS1 might be involved.

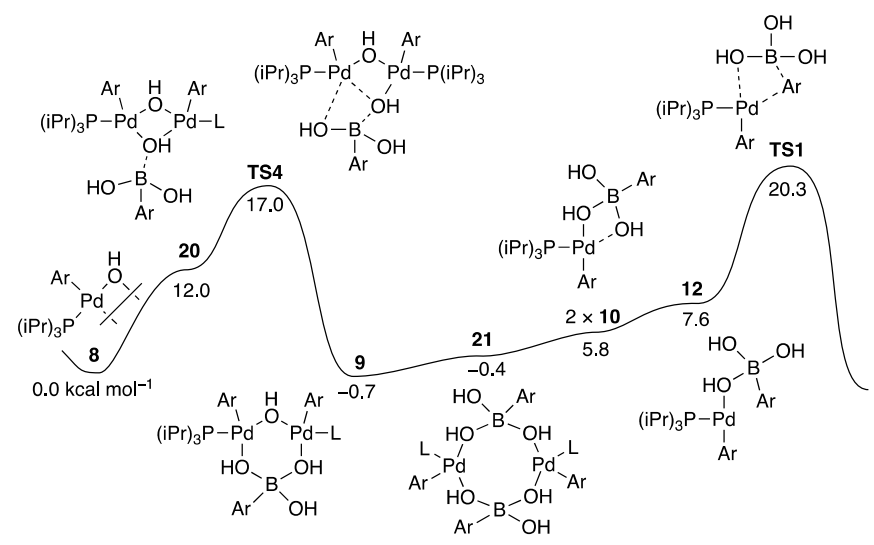

Figure 2: Calculated Gibbs energy profile ( $\mathrm{kcal} \mathrm{mol}^{-1}$ at $293 \mathrm{~K}$ ) for the transmetallation mechanism with $\mathbf{8}$ as the starting material

In the experiments where $\mathbf{8}$ or $\mathbf{9}$ is the starting point, it was assumed that the path to formation of the biaryl product is again through monopalladium species 10. In experiment, formation of the Suzuki-Miyaura coupling product occurs with a rate constant of $8.09 \pm 0.86 \times 10^{-3} \mathrm{~s}^{-1}$ at $263 \mathrm{~K}$, corresponding to an activation Gibbs energy of $17.9 \mathrm{kcal} \mathrm{mol}^{-1}$. Our calculations return an activation Gibbs energy from $\mathbf{9}$ to TS1 of $21.0 \mathrm{kcal} \mathrm{mol}^{-1}$

\subsection{Overall reaction scheme and kinetics}

In the previous sections, we have attempted to explore the level of agreement between experiment and theory for the various individual steps in Suzuki-Miyaura cross-coupling of aryl halides with aryl boronic acids. One of the most valuable resources here with which to gauge the accuracy of the calculations is the set of recent stoichiometric experiments concerning the formation and reactivity of novel pre-transmetallation species with $\mathrm{Pd}-$ $\mathrm{O}-\mathrm{B}$ linkages. The thermodynamic and kinetic observations relating to these species provide an excellent challenge for computation. As was discussed in the previous sections, the agreement with experiment is in general fair, indicating that the computational methods used here are able to model the target reactions, but that significant progress is needed in order to obtain quantitative insight. In particular we note the following points of disagreement: first, in Figure 1, our predicted Gibbs energy of activation for reaction of 6 differs by $10 \mathrm{kcal} \mathrm{mol}^{-1}$ from experiment. Next, we find that computation strongly supports the occurrence of transmetallation through TS1 rather than the experimentally ${ }^{34}$ suggested TS2.

In the present section, however, we wish to instead switch to discussing the level of agreement between experiment and theory concerning reactivity data under catalytic conditions. We consider first the overall thermodynamics of the overall reaction. In the presence of solid base, this can be modelled as $\mathrm{ArBr}+\mathrm{ArB}(\mathrm{OH})_{2}+\mathrm{Na}_{2} \mathrm{CO}_{3} \cdot \mathrm{H}_{2} \mathrm{O}_{(\mathrm{s})} \rightarrow \mathrm{Ar}-\mathrm{Ar}+\mathrm{B}(\mathrm{OH})_{3}+\mathrm{NaHCO}_{3(\mathrm{~s})}$ $+\mathrm{NaBr}_{(s)}$. Under very basic conditions, the product boric acid may be converted to a borate, but this has not been included in the calculations here. Our calculations yield an overall Gibbs energy change for the reaction of $-55.6 \mathrm{kcal} \mathrm{mol}^{-1}$, confirming that the transformation as a whole is highly favoured thermodynamically.

Next we consider the Gibbs energy of the different bottlenecks along the reaction path. In previous work, ${ }^{1}$ we found that for many ligands including $\mathrm{PC}_{3}$ and $\mathrm{PPh}_{3}$, the Gibbs energy barrier for oxidative addition to $\mathrm{Pd}(0)$ species is of the order of $20-25$ $\mathrm{kcal} \mathrm{mol}^{-1}$. The immediate product of oxidative addition is a triscoordinate species ArPdLBr, which is usually slightly lower in Gibbs energy than the starting $\operatorname{Pd}(0)$ species, but can be stabilized by forming dimers with bridging bromide or by adding an extra ligand to form $\mathrm{ArPdL}_{2} \mathrm{Br}$. The relative Gibbs energy of the most stable product of oxidative addition was found ${ }^{1}$ in all cases to be of the order of -15 or $-20 \mathrm{kcal} \mathrm{mol}^{-1}$ with respect to reactants, suggesting that oxidative addition will not in practical terms be reversible under catalytic conditions.

In the present sections $3.1,3.2,3.3$ and 3.4 we consider the sequence of steps going from $\mathrm{ArPdL}_{2} \mathrm{Br}$ to product. Along this route, there are a number of possible bottlenecks. The $X$ to $O$ substitution is the first of these. With typical ligands, both hydroxide and $\operatorname{ArB}(\mathrm{OH})_{3^{-}}$nucleophiles lead to relatively low 
barriers of the order of $15 \mathrm{kcal} \mathrm{mol}^{-1}$, but when considering solid bases and/or bases that are present in a second, aqueous, liquid phase, ${ }^{43}$ this step may nevertheless be demanding due to the low amount of nucleophile present in the organic phase. We calculate that forming the trihydroxyboronate $\mathrm{ArB}(\mathrm{OH})_{3}{ }^{-}$from solid $\mathrm{Na}_{2} \mathrm{CO}_{3}$ requires a standard Gibbs energy change of 18.3 $\mathrm{kcal} \mathrm{mol}^{-1}$, yielding an overall barrier of the order of $30 \mathrm{kcal}$ $\mathrm{mol}^{-1}$. After halide has been replaced by an oxygen nucleophile, one can form one of a variety of different species with a Pd-O-B linkage. With 'normal' phosphines present in a 2:1 or higher ratio to $\mathrm{Pd}$, the most stable of these is $\mathrm{ArPdL}_{2} \mathrm{OB}(\mathrm{OH}) \mathrm{Ar} \mathbf{6}$, while at lower phosphine loading the cyclic dipalladium species 9 may be significant. Interconversion of these different species occurs with relatively low barriers.

Transmetallation itself appears to occur through monopalladium TSs such as TS1, which lie some $20-25 \mathrm{kcal} \mathrm{mol}^{-1}$ above $\mathbf{6}$ or $\mathbf{9}$, though our current calculations find TS1 to lie rather too high compared to $\mathbf{6}$. The diarylpalladium species $\mathbf{1 6}$ formed after the transmetallation step can undergo usually facile reductive elimination to generate product and regenerate the $\operatorname{Pd}(0)$ species that initiates the catalytic cycle. This TS can perhaps in some cases be relatively high in Gibbs energy relative to the coordinatively saturated species $\operatorname{ArPdL}_{2} \mathrm{Ar} 17$, so it cannot be ruled out that it will also form an overall bottleneck to reaction in some cases.

These different bottle-necks are summarized in Figure 3. Given the uncertainties on the calculated Gibbs energies depending on the reaction conditions, on the ligand, but also on the remaining errors in the computations, this Figure should not be interpreted too quantitatively, but it does summarize which steps need to be taken into account. Overall, three steps have Gibbs energy barriers of 25 to $30 \mathrm{kcal} \mathrm{mol}^{-1}$. With the higher of these values, assuming concentrations of most species of the order of $1 \mathrm{M}$, the predicted turnover rate per $\mathrm{Pd}$ atom would be of the order of $0.005 \mathrm{~h}^{-1}$ at $80{ }^{\circ} \mathrm{C}$, whereas barriers of $25 \mathrm{kcal}$ $\mathrm{mol}^{-1}$ predict about 8 turnovers per hour per Pd, roughly similar to observed reactivity in many Suzuki-Miyaura couplings. This suggests that the present calculations overestimate some of the barriers, probably due to underestimating the availability of oxygen nucleophiles.

Compared to one of the most systematically constructed previous overall Gibbs energy diagram for Suzuki-Miyaura cross-coupling, ${ }^{35}$ this diagram differs in a number of respects. First, the oxidative addition TS lies higher in Gibbs energy relative to $P d L_{n}$ reactant species, irrespective of $n$. Next, the $X$ to $O$ substitution TS is shown to play a role in the overall process of transmetallation, together with the actual transmetallation $\mathrm{TS}$, with both lying some $30 \mathrm{kcal} \mathrm{mol}^{-1}$ above the oxidative addition product, once the low concentration of oxygen nucleophiles in the reaction medium is considered. Finally, we show that oxidative addition, $X$ to $O$ substitution, transmetallation and perhaps even reductive elimination have similar Gibbs energy demands, which hints to the difficulties with finding optimal reaction conditions with different substrates.

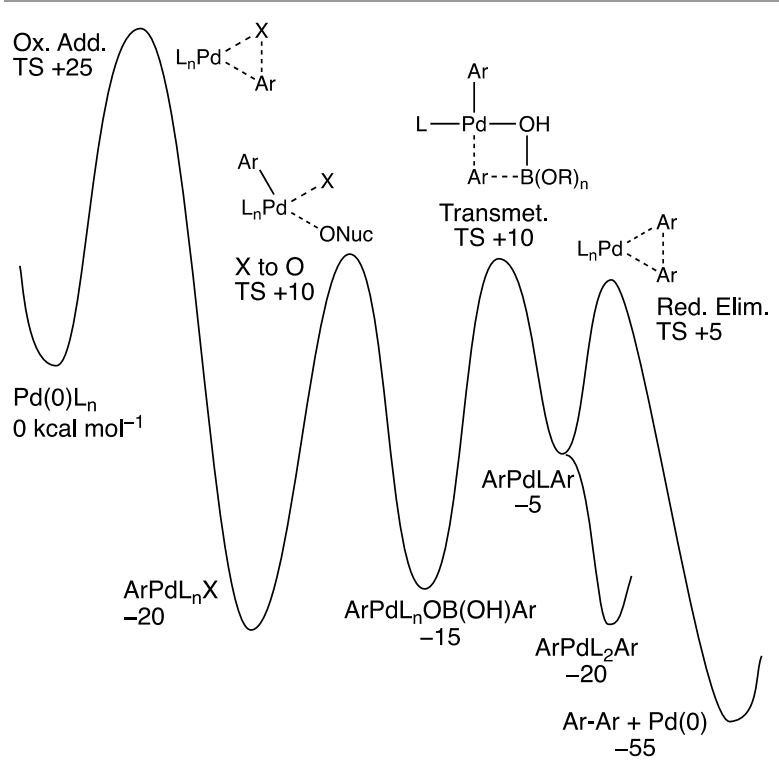

Figure 3. Schematic overall Gibbs energy profile for Suzuki-Miyaura coupling reaction. Indicated relative Gibbs energies are 'best estimates' based on the present calculations with input from experiment, and are provided for guidance only.

\section{Conclusions}

In this paper, we present new quantum chemical calculations relating to the mechanism of Suzuki-Miyaura cross-coupling catalysis by palladium phosphine complexes. Compared to the existing voluminous computational literature on this reaction, there are several new aspects. First, we have extensively characterized the relative Gibbs energies of the range of pretransmetallation species containing a $\mathrm{Pd}-\mathrm{O}-\mathrm{B}$ linkage, reaching broadly good agreement with the experimental results that have recently become available for these species. Next, we have accounted for the Gibbs energy requirements associated with introducing oxygen nucleophiles into the organic phase where the palladium-containing species are usually present. This has the effect of raising the predicted barrier of the $X$ to $O$ substitution step and of the transmetallation step relative to the product of oxidative addition, compared to many previous studies. The remaining significant uncertainties on the calculated Gibbs energies for the oxygen nucleophiles suggest that additional computational and experimental investigation of this aspect is warranted. Finally, we have suggested an overall Gibbs energy profile in which the role of the different steps is summarized, and which shows that a number of steps have similar Gibbs energy requirements. Quantitative agreement with observed turnover behaviour falls far short of what can be achieved for simpler processes, showing that further progress in modelling catalytic kinetics in such complex reactions is still needed. 


\section{Conflicts of interest}

There are no conflicts to declare.
The authors thank Guy Lloyd-Jones for helpful discussions.

\section{Notes and references}

\section{Acknowledgements}

1) a) C. L. McMullin, J. Jover, J. N. Harvey and N. Fey, Dalton Trans. 2010, 39, 10833-10836; b) C. L. McMullin, N. Fey and J. N. Harvey, Dalton Trans. 2014, 43, 13545-13556.

2) E. N. Szlapa and J. N. Harvey, Chem. Eur. J., 2018, 24, 17096 17104.

3) a) N. Miyaura, K. Yamada and A. Suzuki, Tetrahedron Lett. 1979, 20, 3437-3440; b) N. Miyaura and A. Suzuki, J. Chem. Soc., Chem. Commun. 1979, 866-867.

4) N. Miyaura, T. Yanagi and A. Suzuki, Synth. Commun., 1981, 11, 513-519.

5) N. Miyaura and A. Suzuki, Chem. Rev. 1995, 95, 2457-2483.

6) K. Billingsley and S. L. Buchwald, J. Am. Chem. Soc., 2007, 129, 3358-3366

7) H. Doucet, Eur. J. Org. Chem., 2008, 2013-2030.

8) A. F. Littke, C. Y. Dai and G. C. Fu, J. Am. Chem. Soc., 2000, 122, 4020-4028.

9) a) J. R. Racowski, A. R. Dick and M. S. Sanford, J. Am. Chem. Soc. 2009, 131, 10974-10983; b) F. Proutiere, M. Aufiero and F. Schoenebeck, J. Am. Chem. Soc. 2012, 134, 606-612.

10) C. Amatore and F. Pfluger, Organometallics, 1990, 9, 22762282.

11) A. Kurbangalieva, D. Carmichael, K. K. M. Hii, A. Jutand and J. M. Brown, Chem. - Eur. J., 2014, 20, 1116-1125.

12) a) F. Barrios-Landeros and J.F. Hartwig, J. Am. Chem. Soc. 2005, 127, 6944-6945; b) F. Barrios-Landeros, B.P. Carrow and J.F. Hartwig, J. Am. Chem. Soc., 2009, 131, 8141-8154.

13) K. Vikse, T. Naka, J. S. Mclndoe, M. Besora and F. Maseras, Chem CatChem, 2013, 5, 3604- 3609

14) L. Q. Xue and Z. Y. Lin, Chem. Soc. Rev., 2010, 39, 1962-1705.

15) Z. Li, Y. Fu, Q. X. Guo and L. Liu, Organometallics, 2008, 27, 4043-4049.

16) A. A. C. Braga, G. Ujaque and F. Maseras, Organometallics, 2006, 25, 3647-3658.

17) J. Jover, N. Fey, M. Purdie, G. C. Lloyd-Jones and J. N. Harvey, J. Mol. Catal. A: Chem. 2010, 324, 39-47.

18) V. V. Grushin and H. Alper, Chem. Rev., 1994, 94, 1047-1062.

19) R. Martin and S. L. Buchwald, Acc. Chem. Res., 2008, 41, 14611473.

20) E. A. B. Kantchev, C. J. O'Brien and M. G. Organ, Angew. Chem. Int. Ed., 2007, 46, $2768-2813$.

21) N. Hadei, E. A. B. Kantchev, C. J. O'Brien and M. C. Organ, Org. Lett., 2005, 7, 1991-1994.

22) J. F. Hartwig, Acc. Chem. Res. 1998, 31, 852-860.

23) D. A. Culkin and J.F. Hartwig, Organometallics, 2004, 23, 33983416.

24) M. Perez-Rodriguez, A. A. C. Braga, A. R. de Lera, F. Maseras, R. Alvarez, and P. Espinet, Organometallics, 2010, 29, 49834991.

25) V. P. Ananikov, D. G. Musaev and K. Morokuma, Organometallics, 2005, 24, 715-723.

26) D. Zim, V. R. Lando, J. Dupont and A. L. Monteiro, Org. Lett., 2001, 3, 3049-3051.

27) A. A. C. Braga, N. H. Morgon, G. Ujaque, A. Lledos and F. Maseras, J. Organomet. Chem., 2006, 691, 4459-4466.

28) K. Matos and J. A. Soderquist, J. Org. Chem., 1998, 63, 461470.
29) M. Butters, J. N. Harvey, J. Jover, A. J. J. Lennox, G. C. LloydJones and P. M. Murray, Angew. Chem. Int. Ed., 2010, 49, 5156-5160.

30) B. P. Carrow and J. F. Hartwig, J. Am. Chem. Soc., 2011, 133, 2116-2119.

31) C. Amatore, A. Jutand and G. Le Duc, Chem. - Eur. J. 2011, 17 2492-2503.

32) M. A. Ortuno, A. Lledos, F. Maseras and G. Ujaque, ChemCatChem, 2014, 6, 3132-3138.

33) A. A Thomas and S. E. Denmark, Science, 2016, 352, 329-332.

34) A. A. Thomas, H. Wang, A. F. Zahrt and S. E. Denmark, J. Am. Chem. Soc. 2017, 139, 3805-3821.

35) S. Kozuch and J. M. L. Martin, ACS Catal., 2011, 1, 246-253.

36) Z. Liu, C. Patel, J. N. Harvey and R. B. Sunoj, Phys. Chem., Chem. Phys., 2017, 19, 30647 - 30657.

37) Gaussian 16, Revision A.03, M. J. Frisch, G. W. Trucks, H. B. Schlegel, G. E. Scuseria, M. A. Robb, J. R. Cheeseman, G. Scalmani, V. Barone, G. A. Petersson, H. Nakatsuji, X. Li, M. Caricato, A. V. Marenich, J. Bloino, B. G. Janesko, R. Gomperts, B. Mennucci, H. P. Hratchian, J. V. Ortiz, A. F. Izmaylov, J. L. Sonnenberg, D. Williams-Young, F. Ding, F. Lipparini, F. Egidi, J. Goings, B. Peng, A. Petrone, T. Henderson, D. Ranasinghe, V. G. Zakrzewski, J. Gao, N. Rega, G. Zheng, W. Liang, M. Hada, M. Ehara, K. Toyota, R. Fukuda, J. Hasegawa, M. Ishida, T. Nakajima, Y. Honda, O. Kitao, H. Nakai, T. Vreven, K. Throssell, J. A. Montgomery, Jr., J. E. Peralta, F. Ogliaro, M. J. Bearpark, J. J. Heyd, E. N. Brothers, K. N. Kudin, V. N. Staroverov, T. A. Keith, R. Kobayashi, J. Normand, K. Raghavachari, A. P. Rendell, J. C. Burant, S. S. Iyengar, J. Tomasi, M. Cossi, J. M. Millam, M. Klene, C. Adamo, R. Cammi, J. W. Ochterski, R. L. Martin, K. Morokuma, O. Farkas, J. B. Foresman, and D. J. Fox, Gaussian, Inc., Wallingford CT, 2016.

38) S. Grimme, S. Ehrlich and L. Goerigk, J. Comp. Chem., 2011, 32, $1456-1465$.

39) A. V. Marenich, C. J. Cramer and D. G. Truhlar, J. Phys. Chem. B, 2009, 113, 6378-6396.

40) R. F. Ribeiro, A. V. Marenich, C. J. Cramer and D. G. Truhlar, J. Phys. Chem. B, 2011, 115, 14556-14562.

41) For a perspective, see J. N. Harvey, F. Himo, F. Maseras and L. Perrin, to be published.

42) a) S. Miertuš, E. Scrocco and J. Tomasi, J. Chem. Phys., 1981, 55, 117-129; b) S. Miertuš and J. Tomasi, J. Chem. Phys., 1982 65, 239-245; c) J.L. Pascual-Ahuir, E. Silla and I. Tuñón, J. Comp. Chem., 1994, 15, 1127-1138; d) J. Tomasi, B. Mennucci and R. Cammi, Chem. Rev., 2005, 105, 2999-3093.

43) A. J. J. Lennox and G. C. Lloyd-Jones, J. Am. Chem. Soc. 2012, 134, 7431-7441.

44) A. N. Cammidge, V. H. M. Goddard, H. Gopee, N. L. Harrison, D. L. Hughes, C. J. Schubert, B. M. Sutton, G. L. Watts and A. Whitehead, Org. Lett. 2006, 8, 4071-4074.

45) J. A. Gonzalez, O. M. Ogba, G. F. Morehouse, N. Rosson, K. N. Houk, A. G. Leach, P. H. Y. Cheong, M. D. Burke and G. C. LloydJones, Nature Chem., 2016, 8, 1067-1075.

46) R. B. Bedford, N. J. Gower, M. F. Haddow, J. N. Harvey, J. Nunn, R. A. Okopie and R. F. Sankey, Angew. Chem., Int. Ed. 2012, 51, $5435-5438$

47) Experimental data for all species except $\mathrm{Na}_{2} \mathrm{CO}_{3} \cdot \mathrm{H}_{2} \mathrm{O}$ was taken from: P. J. Linstrom and W. G. Mallard, Eds., NIST Chemistry WebBook, NIST Standard Reference Database 
Number 69, National Institute of Standards and Technology, Gaithersburg MD, 20899,https://doi.org/10.18434/T4D303, (retrieved April 23, 2019).

48) For $\mathrm{Na}_{2} \mathrm{CO}_{3} \cdot \mathrm{H}_{2} \mathrm{O}$, data is from T. W. Bauer and R. M. Dorland, Can. J. Chem. 1952, 30, 76-77..
49) A. J. Lennox and G. C. Lloyd-Jones, Angew. Chem. Int. Ed., 2013, 52, 7362-7370.

50) C. Sicre, A. A. C. Braga, F. Maseras and M. M. Cid, Tetrahedron, 2008, 64, 7437-7443.

51) A. A. C. Braga, N. H. Morgon, G. Ujaque and F. Maseras, J. Am. Chem. Soc., 2005, 127, 9298-9307. 